\title{
Effect of Storage on Refined Olive Oil Composition: Stabilization by Addition of Chlorophyll Pigments and Squalene
}

\author{
Ghayth Rigane ${ }^{1,2 *}$, Mohamed Bouaziz ${ }^{3}$, Sami Sayadi ${ }^{3}$ and Ridha Ben Salem ${ }^{1}$ \\ ${ }^{1}$ Laboratoire de Chimie Organique-Physique UR11ES74, Faculté des Sciences de Sfax, B.P «1171», 3000, Sfax, Université de Sfax, Tunisie. \\ ${ }^{2}$ Departement de Physique-Chimie, Faculté Des Sciences et Techniques de Sidi Bouzid, B. P «380», 9100, Sidi Bouzid, Université de Kairouan, \\ Tunisie. \\ ${ }^{3}$ Laboratoire des Bioprocédés Environnementaux, Centre de Biotechnologie de Sfax, B.P «1177» 3018, Sfax, Université de Sfax, Tunisie.
}

\begin{abstract}
Refined olive oil has been analyzed in order to evaluate the influence of storage time on their quality after enrichment with chlorophyll pigments and squalene. At the end of the storage, chlorophyll pigments decomposed for more than $90 \%$, while, carotene pigment loss was lower showing up to $75 \%$ in all oil samples stored at $20^{\circ} \mathrm{C}$ and $50^{\circ} \mathrm{C}$. The reduction of total phenolic compounds exhibited similar degradation profiles, reducing by $81 \%$ for enriched refined olive oil stored at $20^{\circ} \mathrm{C}$ and $50^{\circ} \mathrm{C}$ after six months. For all studied samples, squalene content decreased significantly $(p<0.05)$ only after four months of storage. Oils with added pure squalene had the lower peroxide values $\left(52 \mathrm{meq} \mathrm{O}_{2} \cdot \mathrm{kg}^{-1}\right)$ at the end of storage at $20^{\circ} \mathrm{C}$. After six months of storage the oxidative stability increased to $1 \mathrm{~h} 28 \mathrm{~min}$ and $2 \mathrm{~h} 06 \mathrm{~min}$ for refined olive oil stored at $20^{\circ} \mathrm{C}$ enriched with chlorophyll + squalene and only by squalene, respectively. Therefore, squalene supplemented with $800 \mathrm{mg} \cdot \mathrm{kg}^{-1}$ exhibited favorable antioxidant effects and is preferable for effectively avoiding oxidation. This study could provide useful information for industry to produce high-stability vegetable oil.
\end{abstract}

Key words: refined olive oil, squalene, chlorophyll pigments, Chemlali, oxidative stability

\section{INTRODUCTION}

Olive oil, an excellent natural food, is obtained from olive fruit (Olea europaea, L.) by mechanical or physical procedures. Its composition varies widely, depending on fruit variety, degree of fruit ripeness, environmental conditions, growing region, and techniques of processing and storage. Unfortunately, a great proportion of this oil must be refined to be edible. These oils are susceptible to rapid oxidation during storage due to their low content in polyphenols and losses of oil pigment, mainly chlorophylls, during the extraction process of olive oil ${ }^{1-3)}$.

The relatively short shelf-life of most commercially available vegetable oils limits their usefulness in various applications. A high-stability vegetable oil could be used to reduce inventory turn-over and extend the life of frying oils and fried foods. Highly stable oil could also have application in rations for emergency preparedness, extended space travel, international food-aid and military uses ${ }^{1-3)}$.

Oxidative rancidity development has been recognized as the predominant cause of oil deterioration during storage.
This is a reaction between unsaturated fatty acids, regardless of whether they are in their free state or esterified as a triglyceride molecule, and oxygen. It is also referred to as autoxidation because the activation energies of the first two reaction steps are very low. Therefore, autoxidation in oils can neither be prevented by maintaining cool storage conditions nor by the exclusion of light ${ }^{4}$.

The addition of synthetic oxidation inhibitors to refined edible oils to improve their stability-related properties is a common practice. However, the reported deleterious effects on human health of these synthetic additives such as butylated hydroxyanisole, butylated hydroxytoluene, propyl gallate, or tert-buthylhydroxyquinone have decreased their use and promoted the general consumers' rejections of synthetic food additives ${ }^{1-3)}$. As a result, enrichment of edible oils with natural antioxidants to inhibit or suppress oil oxidation becomes of great interest. The research on vegetable sources and the screening of raw materials for identifying new antioxidants has recently intensified. The large-scale availability of agricultural and

\footnotetext{
*Correspondence to: Dr. Ghayth Rigane, Laboratoire de Chimie Organique-Physique UR11ES74, Faculté des Sciences de Sfax, B.P «1171», 3000, Sfax, Université de Sfax, Tunisie.

E-mail: gaith.rigane@yahoo.fr

Accepted July 8, 2013 (received for review May 28, 2013)
}

Journal of Oleo Science ISSN 1345-8957 print / ISSN 1347-3352 online

http://www.jstage.jst.go.jp/browse/jos/ http://mc.manusriptcentral.com/jjocs 
industrial plant waste materials and their low-cost makes them attractive sources of natural antioxidant ${ }^{5}$. In particular, among the natural antioxidants, phenolic compounds, $\alpha$-tocopherol and $\beta$-carotene, are reported to play a key role in preventing oxidation and have been already correlated to the storage stability of virgin olive oils ${ }^{6-8)}$.

Therefore, the total worldwide consumption of olive oil and the limited virgin olive oil(VOO) production capacity indicate the potential for increasing the range of oils offered to the consumer. The possibilities of developing higher quantities of olive oil, with the same stability characteristics found in virgin olive oil, by the enrichment of refined olive oil with olive leave pigments and squalene have been studied.

The present research is focused on the assessment of quality and stability properties of refined edible oils enriched with chlorophyll pigments and squalene.

\section{MATERIAL AND METHODS}

\subsection{Chemicals}

Methanol, $n$-hexane, cyclohexane and acetic acid HPLCgrade solvents were purchased from Riedel-deHaën (Buchs, Switzerland). Ethanol was obtained from Carlo Erba(Milan, Italy). The solvents were of appropriate purity. Folin-Ciocalteu (F-C) reagent was obtained from Fluka (Buchs, Switzerland). 2, 6, 10, 15, 19, 23-hexamethyl-2, 6, 10, 14, 18, 22 -tetracosahexaene (squalene) were obtained from Sigma Chemical Co. (St. Louis, MO, USA).

\subsection{Plant material}

Refined olive oil sample was obtained from a local commercial refining plant (AGRO- ZITEX, Sfax). Fresh green olive leaves $(200 \mathrm{~g}$ ) were collected from the Chemlali olive tree cultivar commonly cultivated in Tunisia, during 2009/2010 crop from Sfax.

\subsection{Procedure for extraction of chlorophyll pigments from Chemlali olive leaves}

Experiments were carried out on leaves (Olea europaea L.) of Chemlali cultivar commonly cultivated in Sfax (South of Tunisia). Ethanol was added to the olive leaves (100 g) and this was left to stand overnight under agitation in the dark. Subsequently, the solution was filtered using GF/F filter paper. The extract was concentrated in vacuum to dryness at $35^{\circ} \mathrm{C}$ and the residue obtained was redissolved in $5 \mathrm{~mL}$ of ethanol and stored in glass vials at $0^{\circ} \mathrm{C}$ in darkness until its use.

\subsection{Description of samples}

The test material for the study was three series of refined olive oils, which one was considered as control sample (non-enriched refined olive oil), the second one was enriched with $400 \mathrm{mg} \cdot \mathrm{kg}^{-1}$ of chlorophyll pigment extracted from Chemlali olive leaves $+800 \mathrm{mg} \cdot \mathrm{kg}^{-1}$ of pure squalene, while the third series was enriched only with pure squalene $\left(800 \mathrm{mg} \cdot \mathrm{kg}^{-1}\right)$. Weighed quantities of leaves extracts and pure squalene (dissolved in $1 \mathrm{~mL}$ of ethanol and $n$-hexane, respectively) to obtain the desired final molar concentration (400 $\mathrm{mg} \cdot \mathrm{kg}^{-1}$ for chlorophyll pigment and $800 \mathrm{mg} \cdot \mathrm{kg}^{-1}$ of pure squalene). Then, these were added to refined olive oil and stirred for $2 \mathrm{~h}$ in the darkness at room temperature. The samples were stored in the dark, in full filled dark bottles, for six months at temperatures of 20 and $50^{\circ} \mathrm{C}$, and analyzed every ten days of storage. All samples were analyzed three times.

\subsection{Analytical methods}

\subsubsection{Quality indexes determinations}

Peroxide value (meq $\mathrm{O}_{2} \cdot \mathrm{kg}^{-1}$ of olive oil) and the UV absorption for the determination of the extinction coefficients $\mathrm{K}_{232}$ and $\mathrm{K}_{270}$ were measured following the analytical methods described in International Olive Council ${ }^{9}$.

2.5.2 Chlorophyll and carotenoid determination

Chlorophyll and carotenoid compounds $\left(\mathrm{mg} \cdot \mathrm{kg}^{-1}\right.$ of oil) were determined at 470 and $670 \mathrm{~nm}$, respectively, in cyclohexane using the specific extinction values according to the method of Mínguez-Mosquera, et al. ${ }^{10)}$

$$
\begin{aligned}
& \text { Chlorophyll }\left(\mathrm{mg} \cdot \mathrm{kg}^{-1}\right)=\left(\mathrm{A}_{670} \times 10^{6}\right) /(613 \times 100 \times d) \\
& \text { Carotenoid }\left(\mathrm{mg} \cdot \mathrm{kg}^{-1}\right)=\left(\mathrm{A}_{470} \times 10^{6}\right) /(2000 \times 100 \times d)
\end{aligned}
$$

Where $\mathrm{A}$ is the absorbance and $d$ is the path length of the cell $(1 \mathrm{~cm})$. The chlorophyll and carotenoid concentrations are expressed as mg of pheophytin $\alpha$ and lutein per $\mathrm{kg}$ of oil, respectively.

\subsection{Determination of oxidative stability by Rancimat method}

Oxidative stability was evaluated by the Rancimat method. Stability was expressed as the oxidation induction time (h), measured with Rancimat equipment (Metrohm Ltd., Herisau, Swiss), using an oil sample of $5 \mathrm{~g}$ warmed to $120^{\circ} \mathrm{C}$ and an air flow of $10 \mathrm{~L} / \mathrm{h}$. The conductivity cells were filled with $60 \mathrm{~mL}$ of deionized water $(2 \mu \mathrm{S} / \mathrm{cm})$. The time needed for the appearance of a sudden water conductivity rise, caused by the adsorption of volatiles derived from oil oxidation, was registered as the induction time in hours ${ }^{3,11)}$.

\subsection{GC-MS analysis of squalene}

The squalene content of samples was analyzed using a gas-chromatograph with a mass selective detector GC/MS Agilent 5975B inert MSD (Agilent Technologies Inc., Palo Alto, CA, USA $)$, using a capillary column OV-5 $(30 \mathrm{~m} \times 0.25$ $\mathrm{mm}$ and $0.25 \mathrm{~mm}$ film thickness); at a flow rate of 1 $\mathrm{mL} \cdot \mathrm{min}^{-1}$; in electronic impact mode $(70 \mathrm{eV})$; split mode injection (1:20), GC/MS interface at $280^{\circ} \mathrm{C}$ temperature, 
column temperature program was as follows: 100 (1 min) to $300^{\circ} \mathrm{C}$ at $4^{\circ} \mathrm{C} \cdot \mathrm{min}^{-1}(30 \mathrm{~min})$. Squalene was tentatively identified comparing only the mass spectra obtained with those of the Wiley library ${ }^{12,13)}$.

The squalene content of samples was determined by diluting approximately $0.5 \mathrm{~mL}$ of olive oil in $1 \mathrm{~mL} n$-hexane and analyzing the sample solution by GC/MS. Concentrations of squalene contents were then calculated from integrated peak areas of the samples and the calibration curve of squalene standard. Good linearity was achieved in the range $375-3600 \mathrm{mg} \cdot \mathrm{kg}^{-1}\left(\mathrm{y}=62139 \mathrm{x}, \mathrm{r}^{2}=0.986\right)$.

\subsection{Analysis of phenolic compounds}

\subsubsection{Liquid-liquid extraction}

The phenolic extracts were obtained as described before by Rigane, et $a l .{ }^{11)}$ with some modification. Briefly, the oil sample ( $4 \mathrm{~g}$ ) was added to $2 \mathrm{~mL}$ of $n$-hexane and $4 \mathrm{~mL}$ of a methanol/water $(60: 40, \mathrm{v} / \mathrm{v})$ solution in a $20 \mathrm{~mL}$ centrifuge tube. After vigorous mixing, they were centrifuged for 3 min. The hydroalcoholic phase was collected, and the hexanic phase was re-extracted twice with $4 \mathrm{~mL}$ of methanol/water (60:40, v/v) solution each time. Finally, the hydroalcoholic fractions were combined, washed with $4 \mathrm{~mL}$ of $n$-hexane to remove the residual oil, then concentrated and dried by evaporative centrifuge in vacuum at $35^{\circ} \mathrm{C}$.

2.8.2 F-C Test for measurement of total phenol concentration

Briefly, $50 \mu \mathrm{L}$ of phenolic extract was mixed with the Folin- Ciocalteau reagent $(250 \mu \mathrm{L})$ and, with an aqueous solution of $\mathrm{Na}_{2} \mathrm{CO}_{3}(500 \mu \mathrm{L}, 20 \%)$. The mixture was vortexed and diluted with water to final volume of $5 \mathrm{~mL}$. The total phenol content was determined colorimetrically at $765 \mathrm{~nm}$. The standard curve was prepared using diluted solutions of gallic acid in a methanol: water solution $(70$ : $30, \mathrm{v} / \mathrm{v})$. The total phenolic content was expressed as milligrams of gallic acid (GA) equivalents per kilogram of oil. For gallic acid, the curve absorbance versus concentration was described by the equation $\mathrm{y}=0.0017 \mathrm{x}\left(\mathrm{r}^{2}=0.9023\right)^{11,12,14,15)}$.

\subsection{Statistical analysis}

Results of the analytical determinations were expressed as mean \pm standard deviation (SD) of 3 measurements. Statistical differences were calculated using a one-way analysis of variance(ANOVA), employing the Student's $t$-test. Differences were considered significant at $p<0.05$.

\section{RESULTS AND DISCUSSION}

\subsection{Initial composition}

One hundred grams of fresh Chemlali olive leaves yielded $10.8 \mathrm{~g}$ of extract containing $1.59 \mathrm{~g} \cdot \mathrm{kg}^{-1}$ of chlorophyll pigments.

Table 1 presents the results obtained from analysis of
Table 1 Initial composition of refined olive oil sample.

\begin{tabular}{lc}
\hline & Refined olive oil \\
\hline Free acidity $(\%$ oleic acid) & $0.06 \pm 0.00$ \\
$\mathrm{PV}\left(\right.$ meq $\left.\mathrm{O}_{2} \cdot \mathrm{kg}^{-1}\right)$ & $16.2 \pm 0.23$ \\
$\mathrm{~K}_{232}$ & $0.17 \pm 0.02$ \\
$\mathrm{~K}_{270}$ & $0.05 \pm 0.00$ \\
Chlorophyll pigment $\left(\mathrm{mg} \cdot \mathrm{kg}^{-1}\right)$ & $1.27 \pm 0.04$ \\
Carotenoid content $\left(\mathrm{mg} \cdot \mathrm{kg}^{-1}\right)$ & $0.94 \pm 0.06$ \\
Oxidative stability $(\mathrm{h})$ & $4.30 \pm 0.02$ \\
Total phenols $\left(\mathrm{mg} \mathrm{GAE} \cdot \mathrm{kg}^{-1}\right.$ of oil) & $99.4 \pm 0.3$ \\
Squalene content $\left(\mathrm{mg} \cdot \mathrm{kg}^{-1}\right)$ & $250.05 \pm 0.12$ \\
\hline
\end{tabular}

the initial compositions of the refined oil sample used for this study. Peroxide value(PV), conjugated dienes and secondary oxidation products (carbonylic compounds, aldehydes and ketones) were measured by extinction value at 232 and $270 \mathrm{~nm}$. Among the substances with antioxidant properties, the total phenols content was $99.41 \mathrm{mg} \cdot \mathrm{kg}^{-1}$ for refined olive oil expressed as gallic acid equivalent. This low content in phenolic compounds had an effect on the oxidative stability as determined by the Rancimat method (4 hours $30 \mathrm{~min}$ ).

\subsection{Total phenolic contents of chlorophyll rich extract of Chemlali olive leaves}

Total phenolic contents of chlorophyll rich extract of Chemlali olive leaves was $80.75 \pm 0.30 \mathrm{mg}$ GA equivalents • $\mathrm{g}^{-1}$ of ethanolic extract. This result is very low when compared with other study by Lee et al. ${ }^{8)}$ in which total phenolic content of olive leaf extracted by ethanol(80\%) was 148 $\mathrm{mg} \cdot \mathrm{g}^{-1}$.

\subsection{Quality indices}

To determine the effect of the enrichment of refined olive oil by chlorophyll pigment and pure squalene during the storage time in the darkness ( 6 months) on the oil quality, the results of each parameter ( $\mathrm{PV}, \mathrm{K}_{232}$ and $\mathrm{K}_{270}$ ) were compared with values obtained for the control samples (non-enriched) stored in the same conditions $\left(20^{\circ} \mathrm{C}\right.$ and $50^{\circ} \mathrm{C}$ ).

$\mathrm{K}_{232}$ and $\mathrm{K}_{270}$ are simple and useful parameters for assessing the state of oxidation of olive oil. In Fig. 1, it can be seen that after six months of storage, primary and secondary oxidation increases in all the samples. Rate of increase in enriched samples was very slow compared to the control one. On the other hand, the refined olive oil enriched only with squalene show lower levels of absorbance at 232 and $270 \mathrm{~nm}$ than in those enriched with chlorophyll + squalene (Fig. 1).

The changes in PV were similar in all oil samples (Fig. 2). 

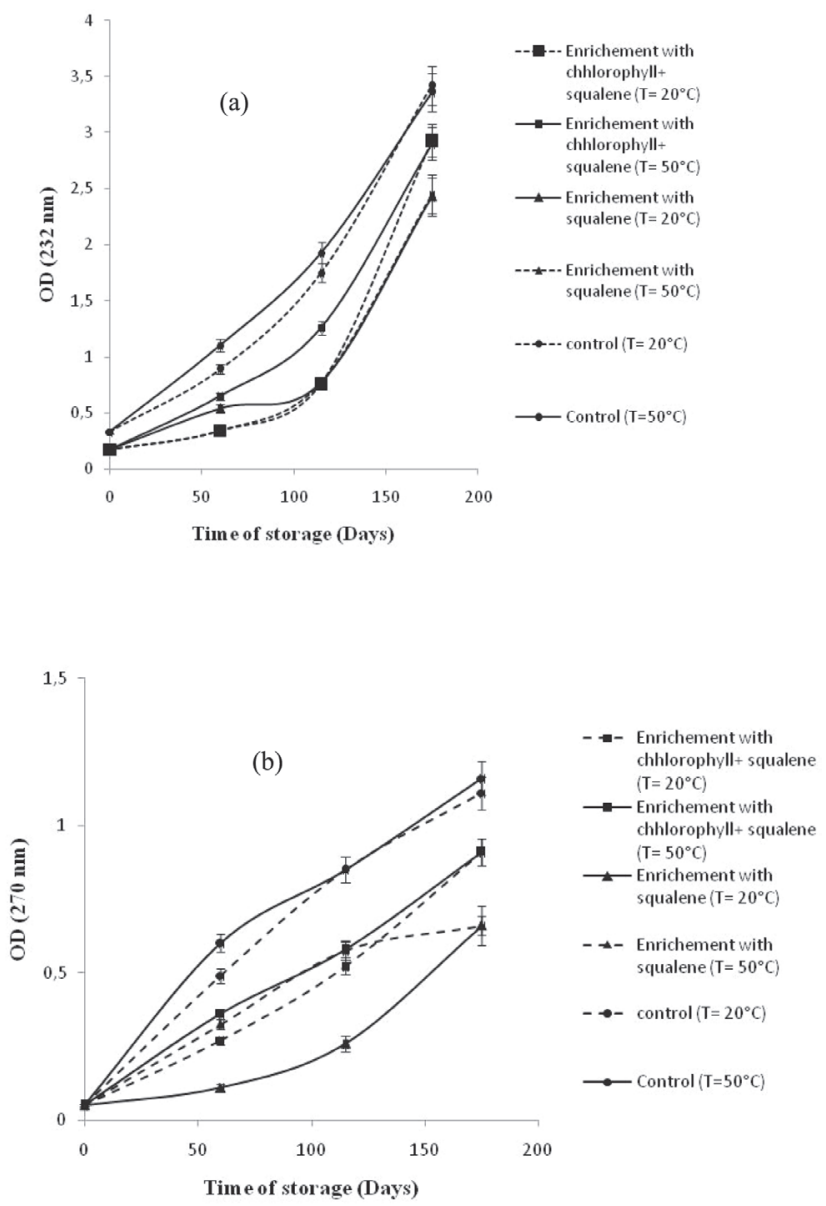

Fig. 1 Changes in the content of conjugated fatty acids measured by the specific extinction coefficient at $232 \mathrm{~nm}\left(\mathrm{~K}_{232}\right)$ (a) and in the content on carbonylic compounds measured by the specific extinction coefficient at $270 \mathrm{~nm}\left(\mathrm{~K}_{270}\right)$ (b). The $\mathrm{SD}$ values were not more than $5 \%$.

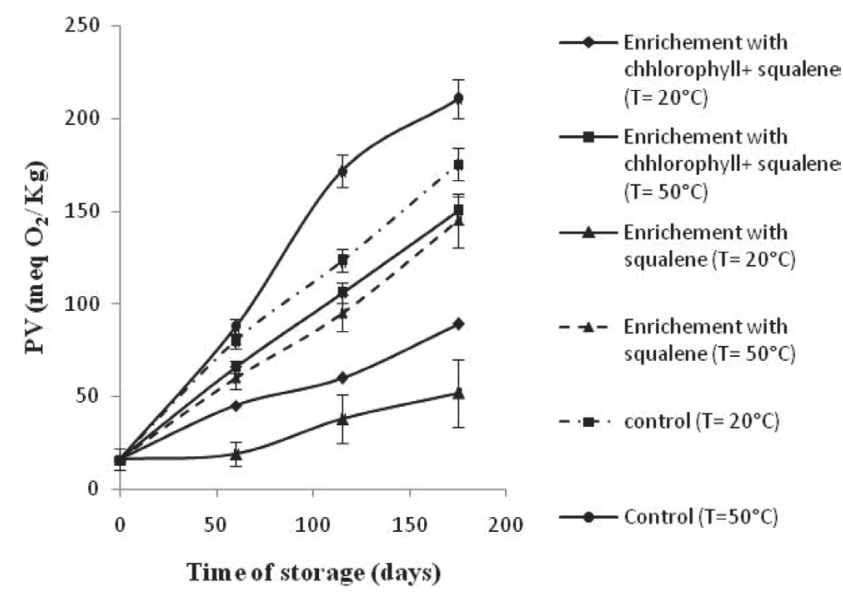

Fig. 2 Change in peroxide value of refined olive oils during storage at 20 and $50^{\circ} \mathrm{C}$. The $\mathrm{SD}$ values were not more than $5 \%$.
An increase in the peroxide value (propagation phase) is produced in all the samples, as, once auto-oxidation is started, it does not stop until all the free radicals that are formed are inactivate ${ }^{16)}$. The enrichment with pure squalene delayed the oxidation of refined olive oil more significantly than with chlorophyll + squalene. As it can be observed in Fig. 2, peroxide values of refined olive oil stored at $20^{\circ} \mathrm{C}$ were below the limit of $20 \mathrm{meq} \mathrm{O}_{2} \cdot \mathrm{kg}^{-1}$ set by the EEC regulations ${ }^{17)}$ for the refined olive oil enriched only with pure squalene after storage for 4 months then it increased to 52 meq $\mathrm{O}_{2} \cdot \mathrm{kg}^{-1}$ at the end of the storage. On the other hand, the PV of enriched refined olive oil with chlorophyll + squalene increased to $60 \mathrm{meq} \mathrm{O}_{2} \cdot \mathrm{kg}^{-1}$ after 4 months of stage at $20^{\circ} \mathrm{C}$. On the contrary, the peroxide values of samples stored at $50^{\circ} \mathrm{C}$ increased dramatically to rich 775 and $150 \mathrm{meq} \mathrm{O}_{2} \cdot \mathrm{kg}^{-1}$, at the end of storage, for control and enriched with chlorophyll + pure squalene, respectively (Fig. 2).

These results were in agreement with those found by Bouaziz, et $a l .^{2,3)}$ and Jaber, et $a l^{18)}$, which reported that enrichment of refined olive oil with phenolic compounds and chlorophyll pigments rich extract recovered from Chemlali olive leaves resulted in an appreciable resistance to oxidative deterioration. In addition, Psomiadou, \& Tsimidou ${ }^{19)}$ claimed that squalene had a protective effect on the oxidative stability of olive oil due to the products of squalene oxidation are quite stable and would not be further involved in propagation reactions.

\subsection{Changes in chlorophyll and carotene contents of re- fined olive oils during storage}

Chlorophylls are responsible for the greenish coloration of certain olive oils. Those pigments are also important in olive oil stability. Figure $3(\mathbf{a})$ presents the change of chlorophyll contents in refined olive oils during storage at $20^{\circ} \mathrm{C}$ and $50^{\circ} \mathrm{C}$. The oil pigment content, mainly the chlorophyll fraction concentration, decreased gradually with the storage time in all samples. Chlorophylls decreased up to $90 \%$ of the initial value at the end of storage at $20^{\circ} \mathrm{C}$ for non- and enriched two series of refined olive oil(Fig. 3 (a)).

Carotenes are present too in olive oil and are responsible for its yellow coloration. Carotenoid content followed a similar trend to that of chlorophylls but the percentage loss was lower showing up to $80 \%$ loss for oil enriched with chlorophyll + squalene stored at $20^{\circ} \mathrm{C}$ and $50^{\circ} \mathrm{C}$, at the end of storage (Fig. 3(b)), while in refined olive oil enriched only with pure squalene, the losses of carotenoid content was $78.72 \%$ from the initial content for samples stored at $20^{\circ} \mathrm{C}$ and $50^{\circ} \mathrm{C}$.

The results of the present study are in accordance with comments reported in previous data obtained in our laboratory when refined olive oil, stored in the same conditions (20 and $50^{\circ} \mathrm{C}$ in the darkness for six months) enriched with 

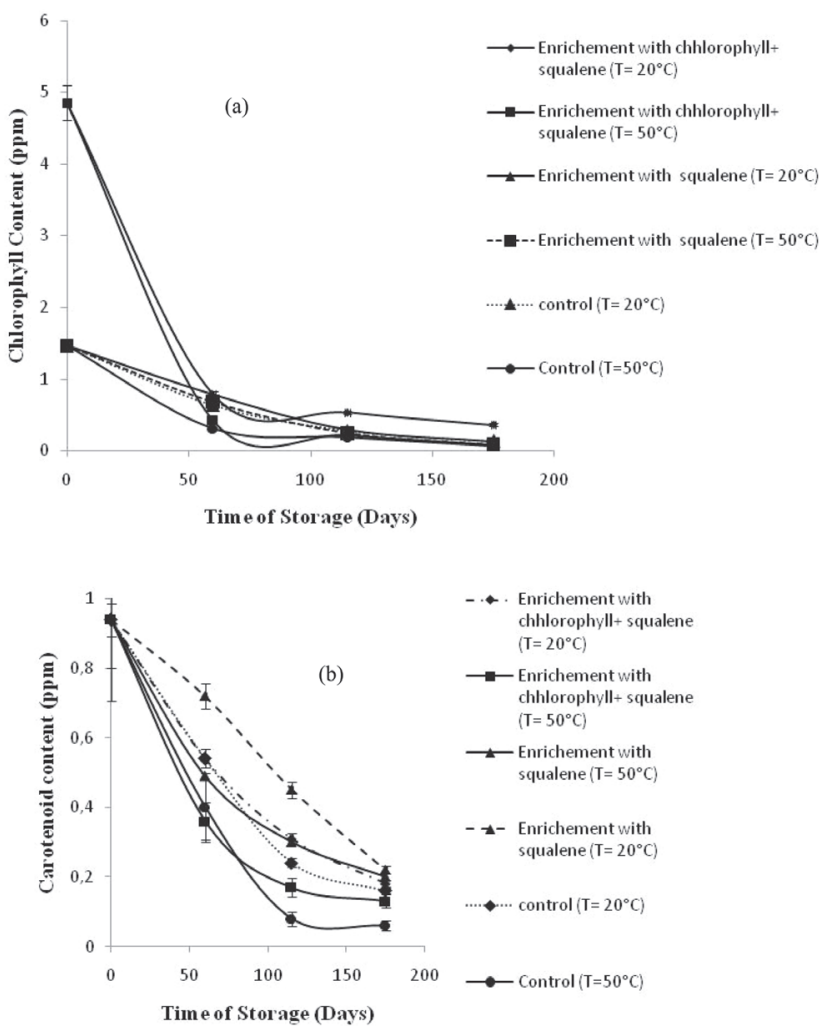

Fig. 3 Chlorophyll (a) and Carotenoid (b) content of refined olive oil stored at 20 and $50^{\circ} \mathrm{C}$. Results are expressed as mean \pm standard deviation of 3 determinations. The SD values were not more than $5 \%$.

$400 \mathrm{mg} \cdot \mathrm{kg}^{-1}$ of chlorophyll pigments extracted from Chemlali olive leaves ${ }^{18)}$.

\subsection{Changes in squalene content during refined oil stor- age}

Squalene, one of the more potent, oil soluble, edible antioxidants, is well absorbed by mammals, protects against various oxidative stresses related diseases, and acts as an anti-carcinogenic and anti-inflammatory agent ${ }^{20)}$.

The squalene content of refined olive oil was $250.05 \mathrm{mg}$. $\mathrm{kg}^{-1}$, this low content of this compound was due to the removal of squalene in the deodorizer distillate during refining. During refining isomerization products of squalene are also produced by the effect of temperature and bleaching earth during the bleaching process.

Measurement of changes in the content of squalene by GC/MS in the present study revealed an insignificant decrease in enriched samples with $400 \mathrm{mg} \cdot \mathrm{kg}^{-1}$ of chlorophyll $+800 \mathrm{mg} \cdot \mathrm{kg}^{-1}$ of squalene and only with $800 \mathrm{mg} \cdot \mathrm{kg}^{-}$ ${ }^{1}$ of pure squalene, stored at $20^{\circ} \mathrm{C}$ after four months of storage ( -29.59 and $-27.72 \%$, respectively), with the exception of enriched samples stored at $50^{\circ} \mathrm{C}(-68.87$ and $38.43 \%$ loss for refined olive oil enriched with chlorophyll

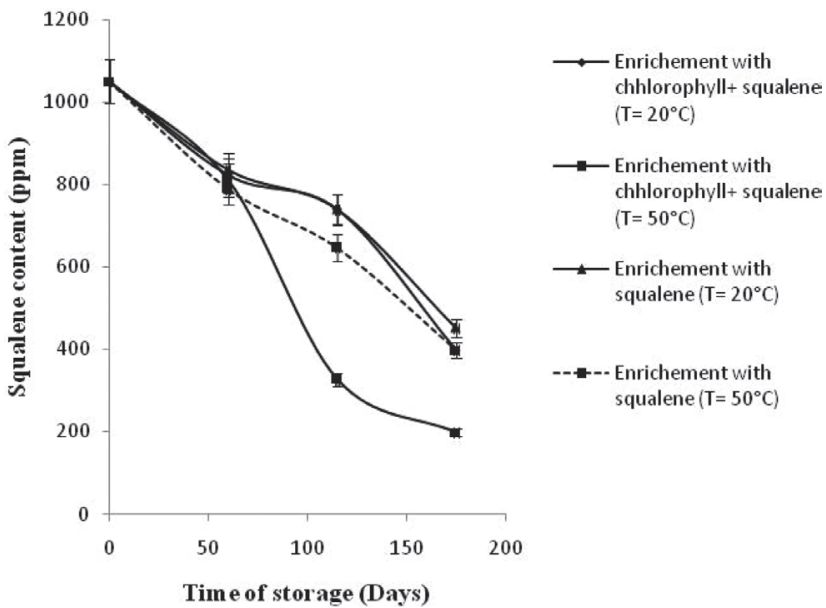

Fig. 4 Changes in squalene during storage of refined olive oil. Results are expressed as mean \pm standard deviation of 3 determinations. The SD values were not more than $5 \%$.

+ squalene and only by squalene, respectively) (Fig. 4). At the end of storage ( 6 months), squalene content decreased for more than $57 \%$ for oil enriched with $800 \mathrm{mg} \cdot \mathrm{kg}^{-1}$ of pure squalene stored at $20^{\circ} \mathrm{C}$ (Fig. 4). Squalene was characterized by the presence of six non-conjugated double bonds, was rather stable at the experimental conditions despite the long storage period.

These results are also in conformity with those indicating a squalene loss ranged between $26-47 \%$ for virgin olive oils stored at room temperature $\left(\sim 25^{\circ} \mathrm{C}\right.$ for 6 months of storage) in the dark ${ }^{21)}$ but not with the low reduction( $10 \%$ ) referred to by Psomiadou, \& Tsimidou ${ }^{19)}$. On the other hand, Rastrelli, et $a{ }^{22)}$ showed that squalene content in Scalicelle $(-45 \%)$ and Terzer $(-51.5 \%)$ olive oil deceased significantly only after 6 months in half-empty bottles, while, they claimed that diffused lighting does not appear to play a significant role in the squalene degradation (Scalicelle, $-19.3 \%$, and Terzera, $-23.8 \%$, after 12 months of storage in the filled colorless bottles at diffused lighting ${ }^{22)}$.

\subsection{Oxidative stability of refined oils}

The refined oils oxidative resistance, measured by Rancimat, was greatly improved in the presence of chlorophyll pigments and squalene (Table 2). Indeed, the induction time of refined olive oil increased significantly from $4 \mathrm{~h} 30$ min to $7 \mathrm{~h} 22$ min by enrichment with chlorophyll rich extract + squalene and to $8 \mathrm{~h} 12 \mathrm{~min}$ with the addition of squalene (Table 2). Moreover, the oxidative oil stability after six months of storage at $20^{\circ} \mathrm{C}$ was influenced by the presence of added compounds. In fact, the oxidative resistances at $120^{\circ} \mathrm{C}$ of refined olive oil increased significantly from 0 h 02 min to 1 h 28 min by enrichment with chlorophyll + squalene and to 2 h 06 min in samples added with 
Table 2 Induction time measured by Rancimat for refined olive oil.

\begin{tabular}{lccc}
\hline & Control & $\begin{array}{c}\text { Refined olive oil with } \\
\text { chlorophyll+ squalene }\end{array}$ & $\begin{array}{c}\text { Refined olive oil with } \\
\text { squalene }\end{array}$ \\
\hline $\begin{array}{l}\text { Induction time at the begging of experiments } \\
(0 \mathrm{~h})\end{array}$ & $4 \mathrm{~h} 30 \mathrm{~min} \pm 0.13^{\mathrm{a}, 1}$ & $7 \mathrm{~h} 22 \mathrm{~min} \pm 0.05^{\mathrm{b}, 1}$ & $8 \mathrm{~h} 12 \mathrm{~min} \pm 0.1^{\mathrm{c}, 1}$ \\
$\begin{array}{l}\text { Induction time at the end of experiments } \\
\text { after } 6 \text { month at } 20^{\circ} \mathrm{C}\end{array}$ & $0 \mathrm{~h} 02 \mathrm{~min} \pm 0.00^{\mathrm{a}, 2}$ & $1 \mathrm{~h} 28 \mathrm{~min} \pm 0.08^{\mathrm{b}, 2}$ & $2 \mathrm{~h} 06 \mathrm{~min}^{\mathrm{m}} \pm 0.05^{\mathrm{c}, 2}$ \\
$\begin{array}{l}\text { Induction time at the end of experiments } \\
\text { after } 6 \text { month at } 50^{\circ} \mathrm{C}\end{array}$ & $0 \mathrm{~h} 02 \mathrm{~min} \pm 0.00^{\mathrm{a}, 2}$ & $0 \mathrm{~h} 45 \mathrm{~min} \pm 0.04^{\mathrm{b}, 3}$ & $1 \mathrm{~h} 19 \mathrm{~min}^{\circ} 0.08^{\mathrm{c}, 3}$ \\
\hline
\end{tabular}

Results are expressed as mean \pm standard deviation of 3 determinations. Significant differences in the same row are shown by different letters $(p<0.05)$. Contents with numbers within time of storage (months) are statistically different at $p<0.05$.

squalene (Table 2). Similarly, the induction period of refined oil stored at $50^{\circ} \mathrm{C}$ augmented from $0 \mathrm{~h} 02$ min to 0 h $45 \mathrm{~min}$ and $1 \mathrm{~h} 19 \mathrm{~min}$ in the presence of chlorophyll + squalene and squalene, respectively (Table 2).

Indeed, previous reports showed that squalene had a protective effect on the oxidative stability ${ }^{23)}$. Bolland, \& Hughes $^{23)}$ suggested the formation of a diperoxide in four steps. From the sequence of reactions it is evident that the peroxy radical cyclizes more efficiently than it abstracts a hydrogen atom from another squalene molecule. The determining factor appears to be a steric one, i.e., the particular spacing of the double bonds must be sufficiently favorable for cyclisation of the peroxy radical. Additionally, it was mentioned that the products of squalene oxidation remain unchanged over a substantial range of oxygen uptake, so that they may not strongly participate in propagation reactions.

Recent work in our laboratory has shown that chlorophyll pigment recovered from Chemlali olive oil increased the oxidative stability of refined oils at the beginning of the study to attend $6 \mathrm{~h} 20 \mathrm{~min}^{18)}$. This low stability of oils enriched with chlorophyll extract was attributed to the latter's low antioxidant capacity as reported by LanferMarquez, et $a l^{24)}$ Therefore, added with squalene (800 mg • $\mathrm{kg}^{-1}$ ) could be responsible for the increase of oxidative stability of studied oils.

\subsection{Phenolic content changes during refined olive oil stor- age}

As the amount of phenolic compounds is an important factor when evaluating the quality of olive oil, because of their involvement in its resistance to oxidation and its sharp bitter taste, this trial also aimed at determining the changes in the phenolic fraction of oils after a 6 month storage period ${ }^{4)}$.

The total phenol content was not completely depleted after storage; it decreased by $78.6 \%$ and by $81 \%$ in refined olive oil enriched with chlorophyll + squalene (Fig. 5). Similar behavior was observed in the second series (refined olive oil with pure squalene) which was characterized by a lower reduction in total phenol content at the end of

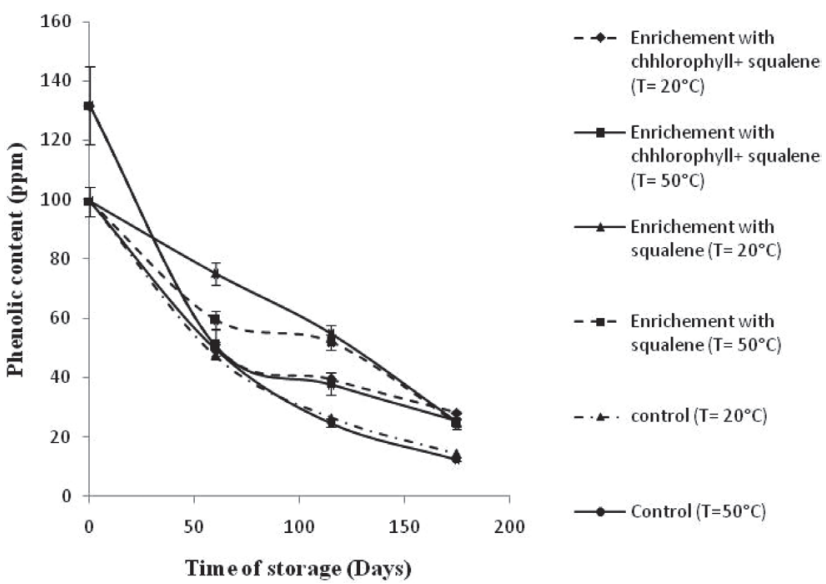

Fig. 5 Total phenol content of refined olive oil stored at 20 and $50^{\circ} \mathrm{C}$. Results are expressed as mean \pm standard deviation of 3 determinations. The SD values were not more than $5 \%$.

storage $\left(74\right.$ and $75 \%$ for refined oil storage at $20^{\circ} \mathrm{C}$ and $50^{\circ} \mathrm{C}$, respectively) (Fig. 5). These results were in accordance with those reported by Bouaziz, et al. ${ }^{3)}$ and Morello, et $a l .{ }^{4)}$

\section{CONCLUSION}

The present paper reports on the study of enrichment of refined olive oils with chlorophyll and squalene. Furthermore, we have demonstrated that squalene could stabilize refined olive oil. It inhibits thermal deterioration of oil by improving its hydrolytic stability, inhibiting double bond conjugation and reducing the formation of second products of oxidation. The results of this study could be interesting for refined olive oil packagers and marketers to estimate the caducity date of refined quality oil.

\section{Acknowledgments}

The authors thank the Tunisian Ministry of Higher Edu- 
cation and Scientific Research for financial support and are grateful to Professor Mohamed Rigane for useful discussions about the English.

\section{References}

1) Giuffrida, D.; Salvo, F.; Salvo, A.; La Pera, L.; Dugo, G. Pigments composition in monovarietal virgin olive oils from various sicilian olive varieties. Food Chem. 101, 833-837, (2007).

2) Bouaziz, M.; Feki, I.; Jemai, H.; Ayadi, M.; Sayadi, S. Effect of storage on refined and husk olive oils composition: Stabilization by addition of natural antioxidants from Chemlali olive leaves. Food Chem. 108, 253-262, (2008).

3) Bouaziz, M.; Feki, I.; Ayadi, M.; Jemai, H.; Sayadi, S. Stability of refined olive oil and olive pomace oil added by phenolic compounds from olive leaves. Eur. J. Lipid Sci. Techo. 112, 21-24, (2010).

4) Morello, J. R.; Motilva, M. J.; Tovar, M. J.; Romero, M. P. Changes in commercial virgin olive oil (cv Arbequina) during storage, with special emphasis on the phenolic fraction. Food Chem. 85, 357-364, (2004).

5) Perez-Bonilla, M.; Salido, S.; Van Beek, T. A.; LinaresPalomino, P. J.; Altarejos, J.; Nogueras, M.; Sanchez, A. Isolation and identification of radical scavengers in olive tree (Olea europaea) wood. J. Chrom A, 1112, 311-318, (2006).

6) Bouaziz, M.; Sayadi, S. Isolation and evaluation of antioxidants from leaves of a Tunisian cultivar olive tree. Eur J Lipid Sci Technol, 107, 497-504, (2005).

7) Méndez, A.I.; Falqué, E. Effect of storage time and container type on the quality of extra-virgin olive oil. Food Cont. 18, 521-529, (2007).

8) Lee, O. H.; Lee, B. Y.; Lee, J.; Lee, H. B.; Son, J. Y.; Park, C. S.; Shetty, K.; Kim, Y. C. Assessment of phenolics-enriched extract and fractions of olive leaves and their antioxidant activities. Bio. Technol. 100, 6107-6113, (2009).

9) International Olive Council, COI/T,15/NC n 3 Rev 5, November 2010, Principe de Vergara, 154, 28002, Madrid, España.

10) Mínguez-Mosquera, M. I.; Rejano, L.; Gandul, A.; Sanchez, B. H.; Garrido, J. Color-pigment correlation in virgin olive oil. J. Am Oil Chem. Soc. 68, 322-337, (1991).

11) Rigane, G.; Ayadi, M.; Boukhris, M.; Sayadi, S.; Bouaziz M. Characterization and phenolic profiles of two rare olive oils from southern Tunisia: Dhokar and GemriDhokar cultivars. J. Sci. Food Agric. 93, 527-534, (2013).
12) Rigane, G.; Boukhris, M.; Bouaziz, M.; Sayadi, S.; Ben Salem, R. Analytical evaluation of two monovarietal virgin olive oils cultivated in South of Tunisia: JemriBouchouka and Chemlali-Tataouin cultivars. J. Sci. Food Agric. 93, 1242-1248, (2013).

13) Grigoriadou, D.; Androulaki, A.; Psomiadou, E.; Tsimidou, M. Z. Solid phase extraction in the analysis of squalene and tocopherols in olive oil. Food Chem. 105, 675-680,(2007).

14) Rigane, G.; Ben Salem, R.; Sayadi, S.; Bouaziz, M. Phenolic composition, isolation and structure of a new deoxyloganic acid derivative from Dhokar and GemriDhokar olive cultivars. J. Food Sci. 76, 965-973, (2011).

15) Singleton, V. L.; Rossi, J. A. Colorimetry of total phenolics with phosphomolybdicphosphotungstic acid reagents. Am J Enol Viticult. 16, 144-158, (1965).

16) Kiritsakis, A. K. El aceite de oliva. Ediciones A. Madrid Vicente. Madrid, Spain(1992).

17) European Union Commission Regulation (EEC) 1989/ 2003. Characteristics of olive and olive pomace oils and their analytical methods. Off J. Eur. Com. 295, 57-66, (2003).

18) Jaber, H; Ayadi, M; Makni, J.; Rigane, G.; Sayadi, S.; Bouaziz, M. Stabilization of refined olive oil by enrichment with chlorophyll pigments extracted from Chemlali olive leaves. Eur. J. Lipid Sci. Technol. 114, 1274-1283, (2012).

19) Psomiadou, E.; Tsimidou, M. Stability of virgin olive oil. 1. Autoxidation studies. J. Agric. Food Chem. 50, 716-721,(2002).

20) Owen, R. W.; Mier, W.; Giacosa, A.; Hull, W. E.; Spiegelhalder, B.; Bartsch, H. Phenolic compounds and squalene in olive oils: The concentration and antioxidant potential of total phenols, simple phenols, secoiridoids, lignans, and squalene. Food Chem. Toxicol. 38, 647$659,(2000)$.

21) Manzi, P.; Panfili, G.; Esti, M.; Pizzoferrato, L. Natural antioxidants in the unsaponifiable fraction of virgin olive oils from different cultivars. J. Sci. Food Agric. 77, 115-120, (1998).

22) Rastrelli, L.; Passi, S.; Ippolito, F.; Vacca, G.; De Simone, F. Rate of Degradation of $\alpha$-Tocopherol, Squalene, Phenolics, and Polyunsaturated Fatty Acids in Olive Oil during Different Storage Conditions. J. Agric. Food Chem. 50, 5566-5570, (2002).

23) Bolland, J. L.; Hughes H. The primary thermal oxidation product of squalene. J. Chem. Soc. 26, 492-497, (1949).

24) Lanfer-Marquez, U. M.; Barros, R. M. C.; Sinnecker, P. Antioxidant activity of chlorophylls and their derivatives. Food Res. Inter. 38, 885-891, (2005). 